\title{
Questa è public history? I meme e la storia
}

\author{
Di Igor Pizzirusso, Gabriele Sorrentino, Iara Meloni, Francesco Mantovani e Matteo Di Legge
}

Mar 12, 2019 | In evidenza, Storia pubblica $|\underline{0}|$

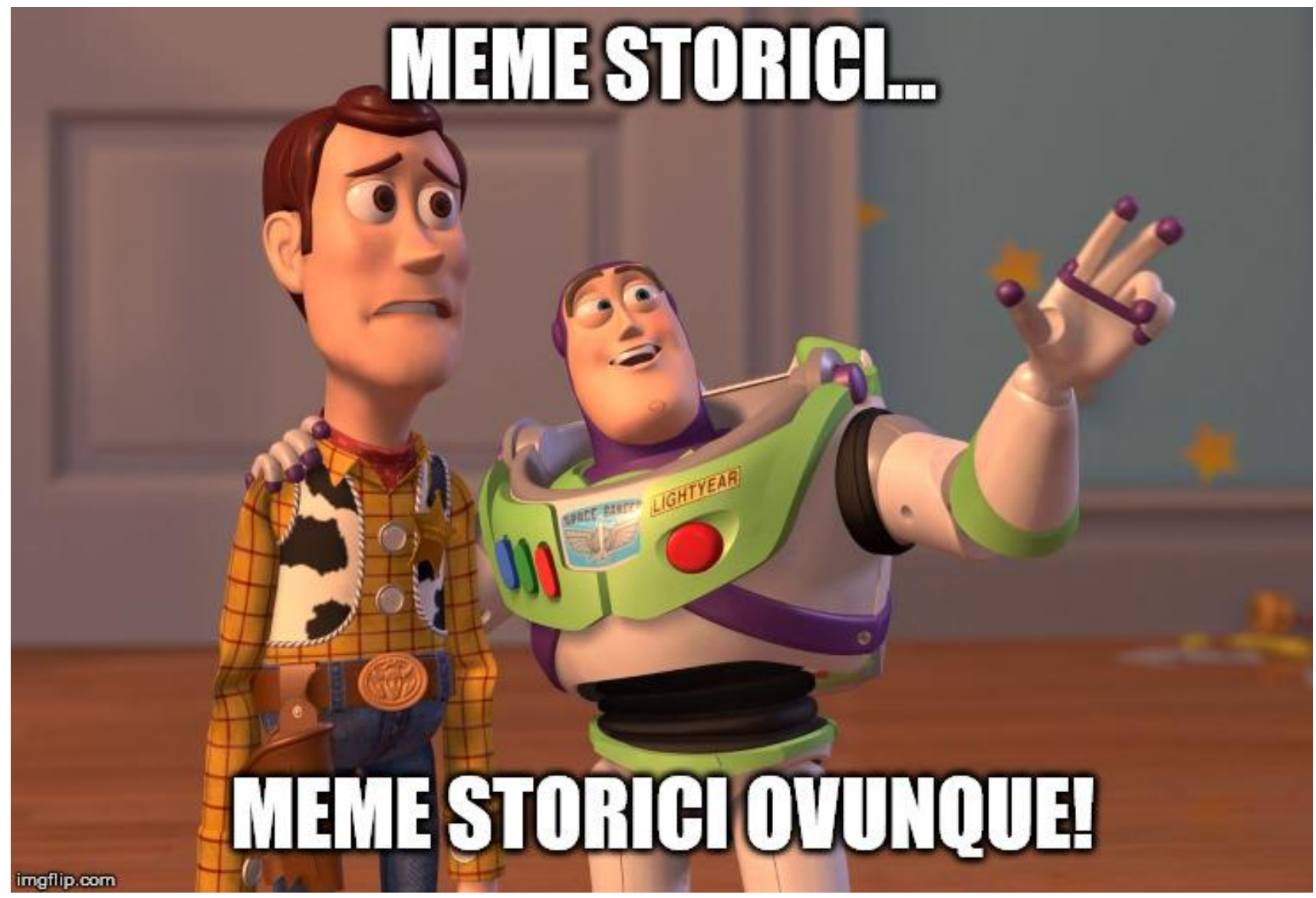

Meme realizzato dagli autori sul sito ImgFlip usando la nota immagine del cartone animato Toy Story

\begin{abstract}
Come è noto, Internet è popolato da una gran numero di fenomeni. Alcuni di loro appartengono alle sottoculture, altri (magari nati proprio tra queste sottoculture) diventano mainstream, diffondendosi da una comunità online a un'altra e acquisendo nuovi significati e funzioni. Da questo punto di vista, i meme ne rappresentano uno degli esempi più visibili e rilevanti, sia da un punto di vista qualitativo che quantitativo. Si tratta di un prodotto culturale complesso, generato dall'unione fra più unità semantiche, tipicamente una o più immagini accompagnate da didascalia. L'approdo sui social network ha fatto sì che i meme abbracciassero una serie assai vasta di tematiche, tra cui anche la storia: come negli altri casi, l'accostamento di immagini o scritte appartenenti alla cultura "pop" a contenuti storici provoca nella maggior parte dei casi la risata. Alcuni di questi riescono addirittura a riassumere - seppur in maniera semplificata - questioni storiche anche molto complesse. L'articolo riflette se ciò sia sufficiente a determinare se i meme siano o meno strumenti utili per parlare di storia con un pubblico che ha dimestichezza coi linguaggi del web.
\end{abstract}




\section{Testo che rielabora la ricerca dagli autori presentata in un panel alla 2a Conferenza italiana di Public History (Pisa 11-15 giugno 2018)}

\section{Alcune definizioni}

Benché il concetto di meme risalga in realtà al 1979 e alla pubblicazione del volume "The Selfish Gene" (Il gene egoista) di Richard Dawkins, la prima vera definizione rintracciabile del fenomeno risale al 2009 ed è di Patrick Davison[1]: "Un meme di Internet è un pezzo di cultura, in genere uno scherzo, che acquista influenza attraverso la trasmissione online".

Nel 2012 la Treccani inserisce il lemma nella sua enciclopedia, con la seguente defizione: «Singolo elemento di una cultura o di un sistema di comportamento, replicabile e trasmissibile per imitazione da un individuo a un altro o da uno strumento di comunicazione ed espressione a un altro (giornale, libro, pellicola cinematografica, sito internet, ecc.)[2]»

Nel 2017 è poi la volta di Alessandro Lolli[3] e Amanda Brennan[4], che rispettivamente danno le seguenti definizioni: «Il meme è l'unione di più unità semantiche che bisogna conoscere per comprendere l'insieme e solo di conseguenza, eventualmente, riderne» e «un'elemento di cultura definito dalle persone che lo usano e che viene mutato lungo la strada»[5].

\section{Le ragioni del successo dei meme}

Ciò premesso, si può già intuire quali ragioni abbiano determinato la grande diffusione dei meme. Oltre alla materia divertente, il segreto del loro successo alla fine degli anni ' 90 e all'inizio degli anni 2000 è da ricercarsi essenzialmente in cinque fattori principali: la possibilità di crearli fornita da un numero sempre maggiore di programmi di editing grafico e internet; l'adattabilità a un'ampia gamma di usi, comunicando barzellette, emozioni, persino pubblicità; la loro facilità di padronanza, dal momento che la maggior parte di essi sono realizzati usando le funzioni di copia-incolla del testo; la loro accessibilità, che dipende dall'accessibilità del loro habitat, ovvero Internet; infine la trasferibilità, relativa alla loro qualità più importante, rappresentata dalla replicabilità in diverse culture[6].

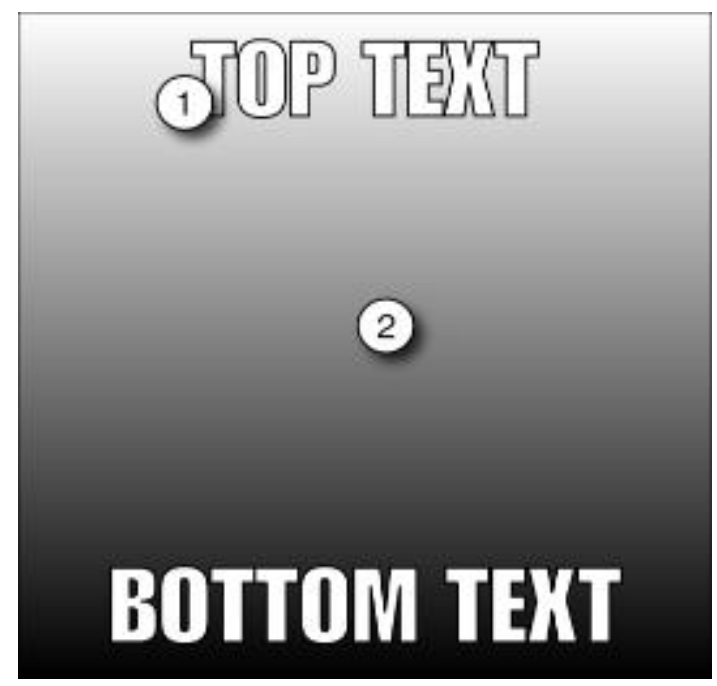

Struttura tipica dei meme più semplici, creati utilizzando le «immagini macro»: 1) testo in font Impact; 2) immagine. 


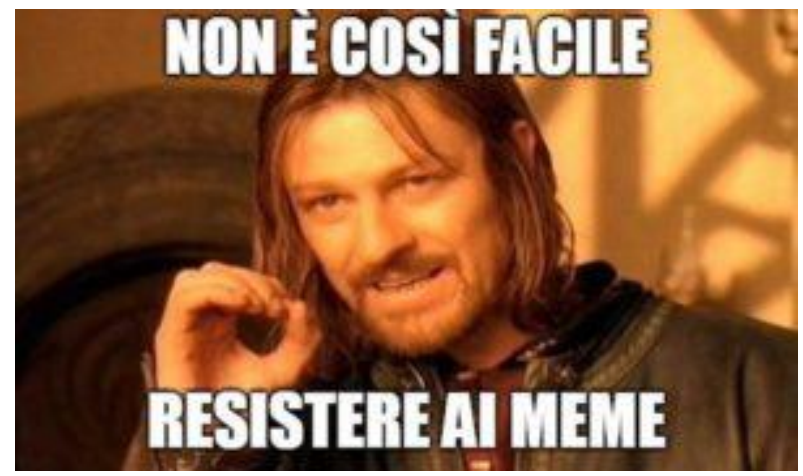

Un esempio che utilizza un'immagine nota tratta dal famoso film "Il Signore degli anelli"

Inoltre, come emerge dalla definizione data da Brennan, l'alta generatività dei meme riadattati implica non solo la condivisione online ma anche la partecipazione degli utenti, stimolati a introiettare, modificare e ripubblicare in modo anonimo la battuta.

\section{Perché studiare i meme}

A differenza degli altri contenuti virali diffusi sul web i meme non mirano semplicemente a riprodursi, cioè a "infettare" gli utenti che li ripropongono senza modificarli, quanto a reinventarsi grazie all'attività degli utenti stessi, produttori e consumatori al tempo stesso (prosumer). Questo, oltre a essere uno dei pilastri della public history, è anche uno dei requisiti del cosiddetto web 2.0. E non è infatti un caso che lo sviluppo dei meme sia stato esponenziale a partire dalla diffusione del web partecipato e dei social network. Così, di pari passo, è cresciuta anche l'attenzione sul fenomeno da parte degli studiosi di diverse discipline, quali ad esempio comunicazione, sociologia e filosofia. Alcuni studi (quello di Börzsei nel 2013 ne è un esempio[7]) mostrano l'umorismo dei meme di internet cambiare la nostra percezione del mondo; altri evidenziano il loro linguaggio ambiguo e il parallelismo con gli stili di propaganda di "alt-destra" e "supremazia bianca" (Angela Nagle nel 2017[8] ma anche Alessandro Lolli, lo stesso anno[9]); inoltre, alcuni studiosi (come Knobel e Lankshear nel lontano 2005[10]) sostengono come il processo di "meming", cioè produrre o "remixare" un meme, possa risultare una pratica fruttuosa per gli educatori di concentrarsi sulle nuove forme di partecipazione sociale attraverso Internet.

Più in generale, è difficile negare come attraverso essi sia oggi possibile rintracciare temi, questioni e comportamenti delle società glocali; o ignorare che in molti casi, i meme abbiano raggiunto un potere persino simile a quello dei manifesti propagandistici. 


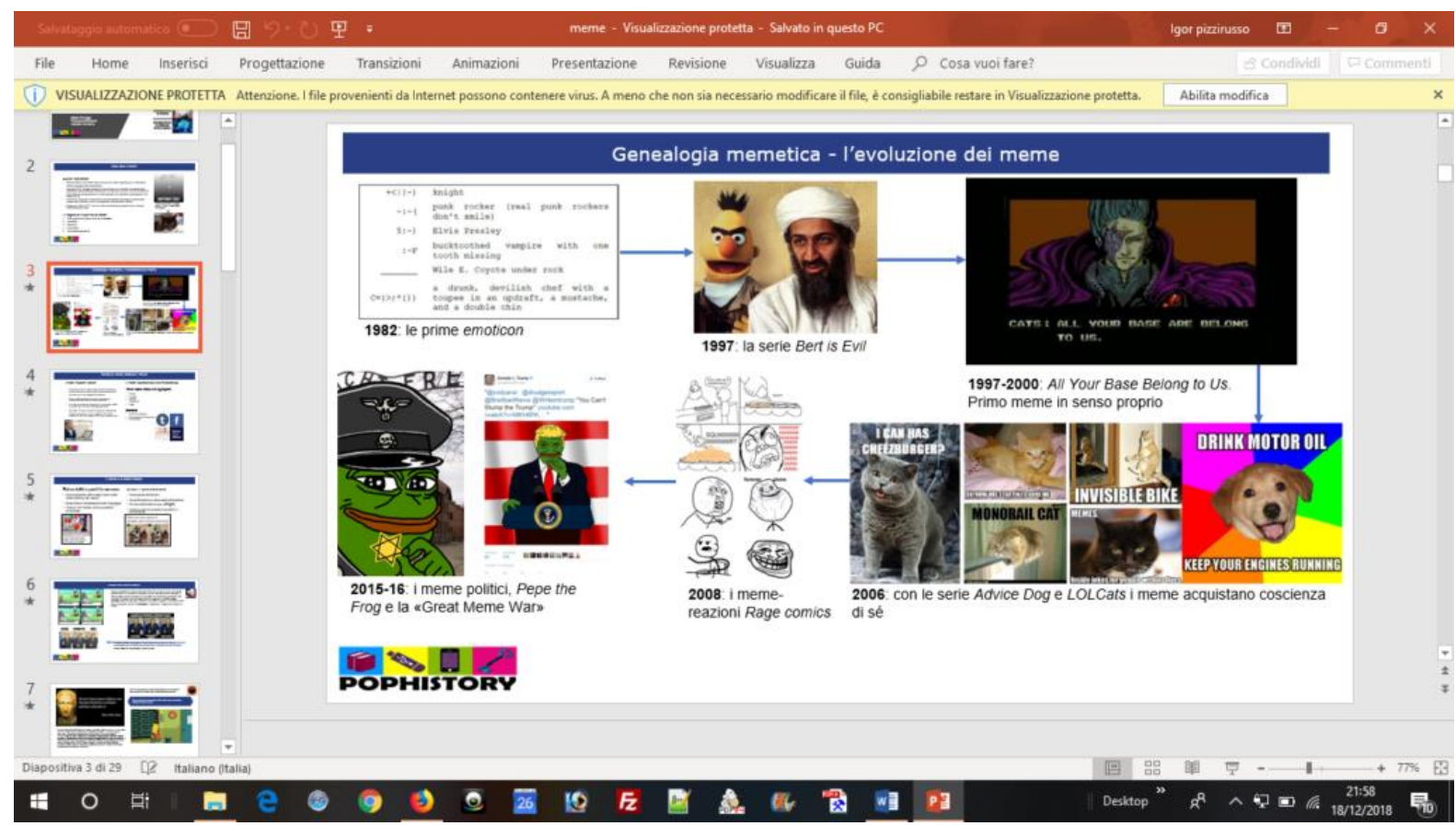

Breve antologia/genealogia dei meme più famosi (fonti: KnowYourMeme e Börzsei 2013)

\section{Le fonti: ricostruendo la filiera memetica}

A questo punto ci si potrebbe (e dovrebbe) chiedere dove sono gli archivi e le biblioteche in cui è possibile studiare, raccogliere dati e verificare questo argomento. Gran parte dell'attuale letteratura sui meme presta particolare attenzione a diversi tipi di fonti: da un lato abbiamo i siti web in cui vengono creati e diffusi, ad esempio forum o blog (4chan, Tumblr); dall'altri ci sono invece siti web che fungono da aggregatori (9GAG, Reddit) e i social media (Facebook). Di notevole utilità e interesse sono infine i database che essenzialmente spiegano l'origine e lo sviluppo di ogni singolo meme. Tra questi, KnowYourMeme è probabilmente il più accurato e dettagliato, ma non sono da sottovalutare nemmeno Encyclopadia Dramatica e Memebase.

\section{I meme legati alla storia o la storia attraverso i meme?}

Allo scopo di indagare meglio il fenomeno e le sue implicazioni, ci pare a questo punto fondamentale analizzare diversi esempi di meme, suddivisi per tema ed epoca storica.

\section{Storia romana}

Giulia, Augusto e i Pokemon: Il meme riprende la rediviva moda dei Pokemon, un gioco in cui, a seconda dell'avversario, è necessario scegliere il giusto campione per la battaglia. Il Meme adatta questa meccanica, in maniera tutto sommato grossolana, alle vicende di Augusto e di sua figlia Giulia che, appunto, si ribella al Mos Maiorum impostole dal padre. Ebbene, è possibile cogliere l'ironia della scena solo conoscendo il gioco dei Pokemon e, soprattutto, i rapporti tra Augusto e Giulia. 


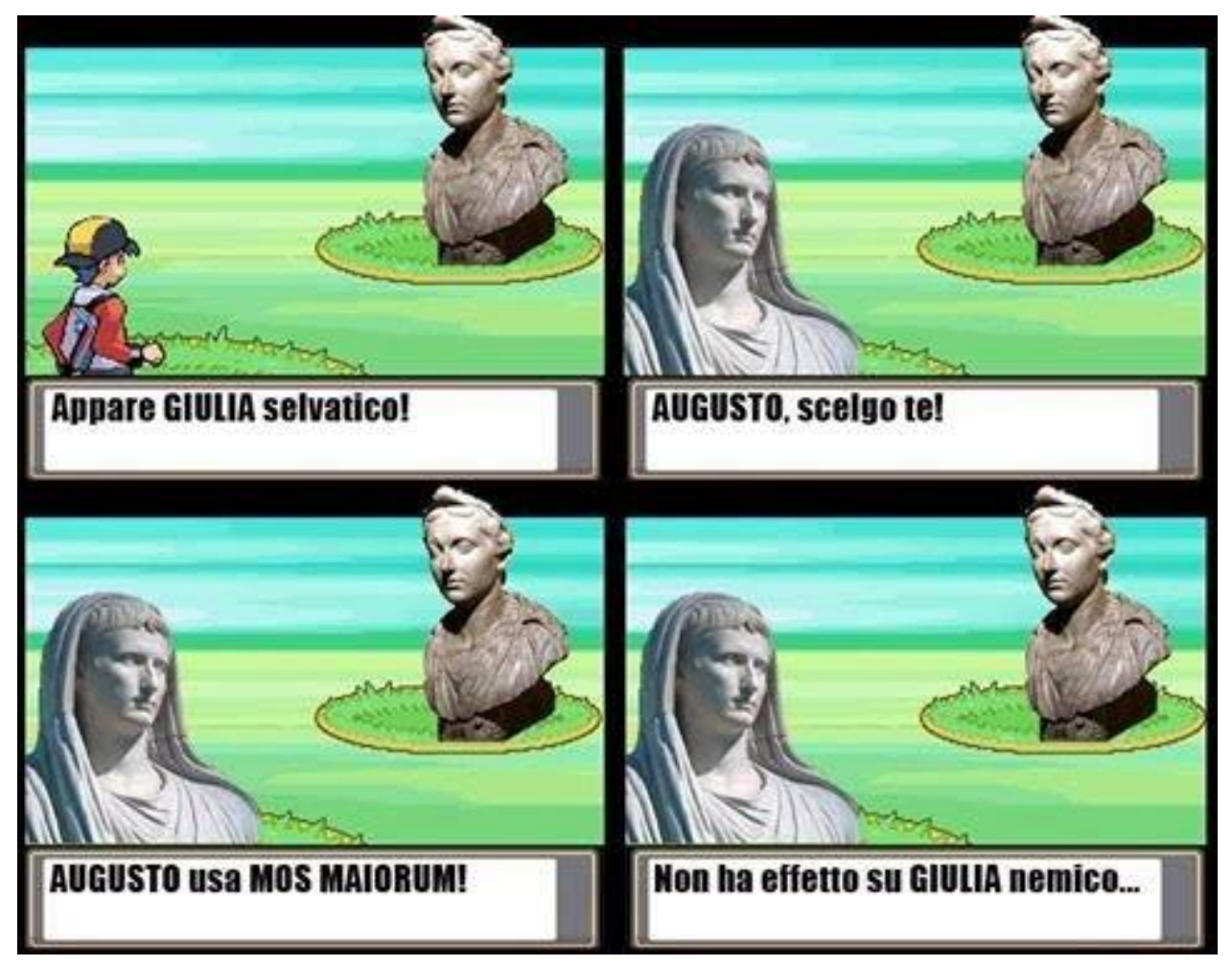

Un altro meme sull'Impero Romano molto interessante è quello che mostra l'immagine dell'assassinio di Giulio Cesare con il testo: "Nulla è più terribile di una delusione d'amore, tranne il tradimento di Bruto". Il meme è interessante perché unisce un tema caro all'adolescenza - le pene d'amore - con un tema storico che viene studiato proprio a cavallo dell'adolescenza, di solito nelle seconde classi delle scuole secondarie. Il meme, inoltre, precisa che il tradimento di Bruto ha portato la guerra civile e la fine della Repubblica, fornendo una seppur semplice nozione storica di contesto. 

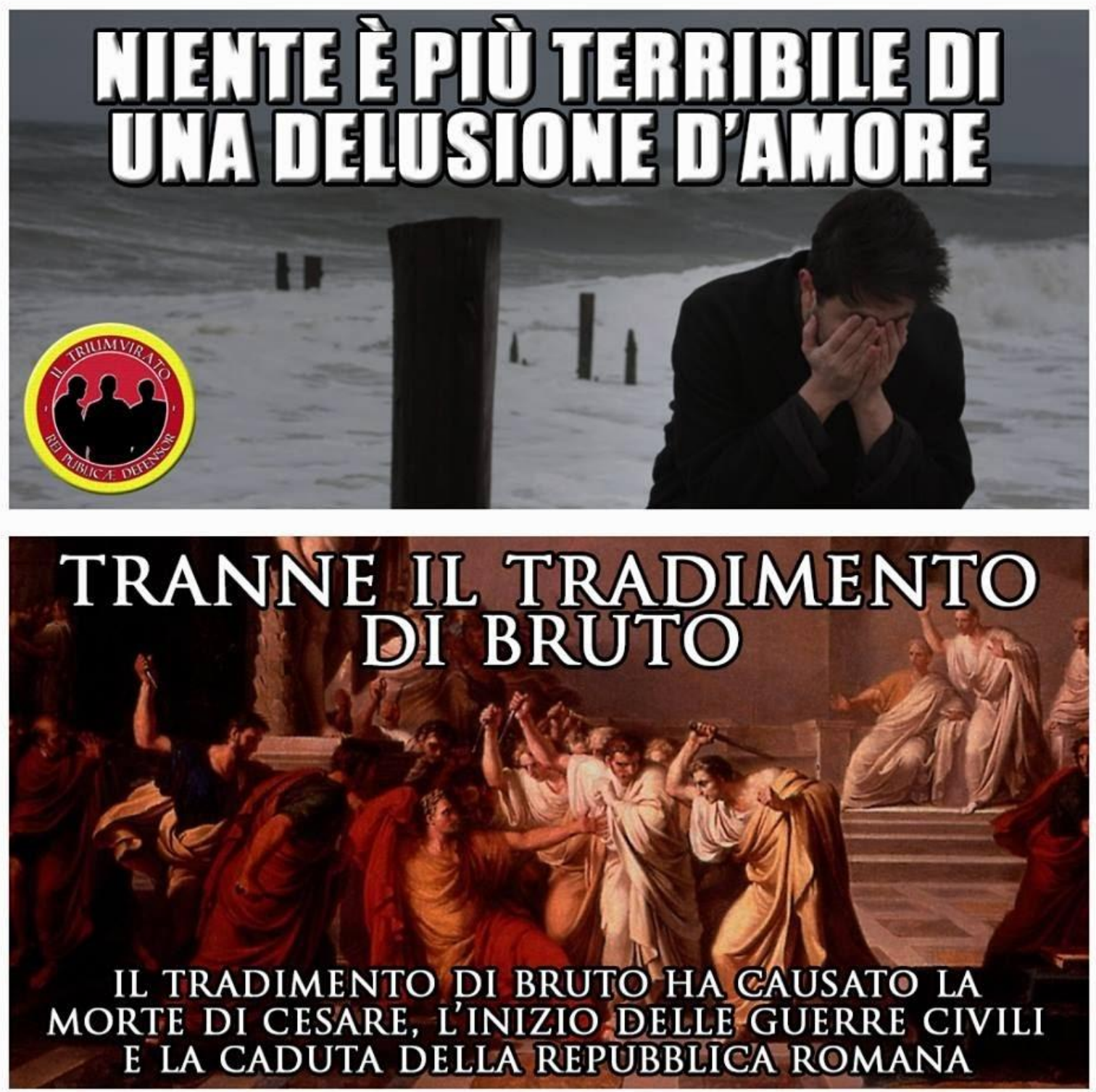

Un altro meme molto diffuso - e declinato in una vastissima gamma di versioni e argomenti riguarda il protagonista dei Muppets Kermit la rana, raffigurato con atteggiamento incurante e rilassato mentre sorseggia del tè. All'immagine vengono abbinate sovente frasi che enfatizzano questo atteggiamento, cosa che puntualmente avviene anche in quella sottostante, dove lo si vede vestito da legionario, ironizzare sulle invasioni dei Sassoni nella rissosa provincia di Britannia. L'accostamento suscita ilarità anche senza conoscere la storia della Britannia romana, ma di certo chi la conosce riesce a cogliere il significato in maniera più profonda (e di conseguenza a ricavarne maggiore divertimento). 


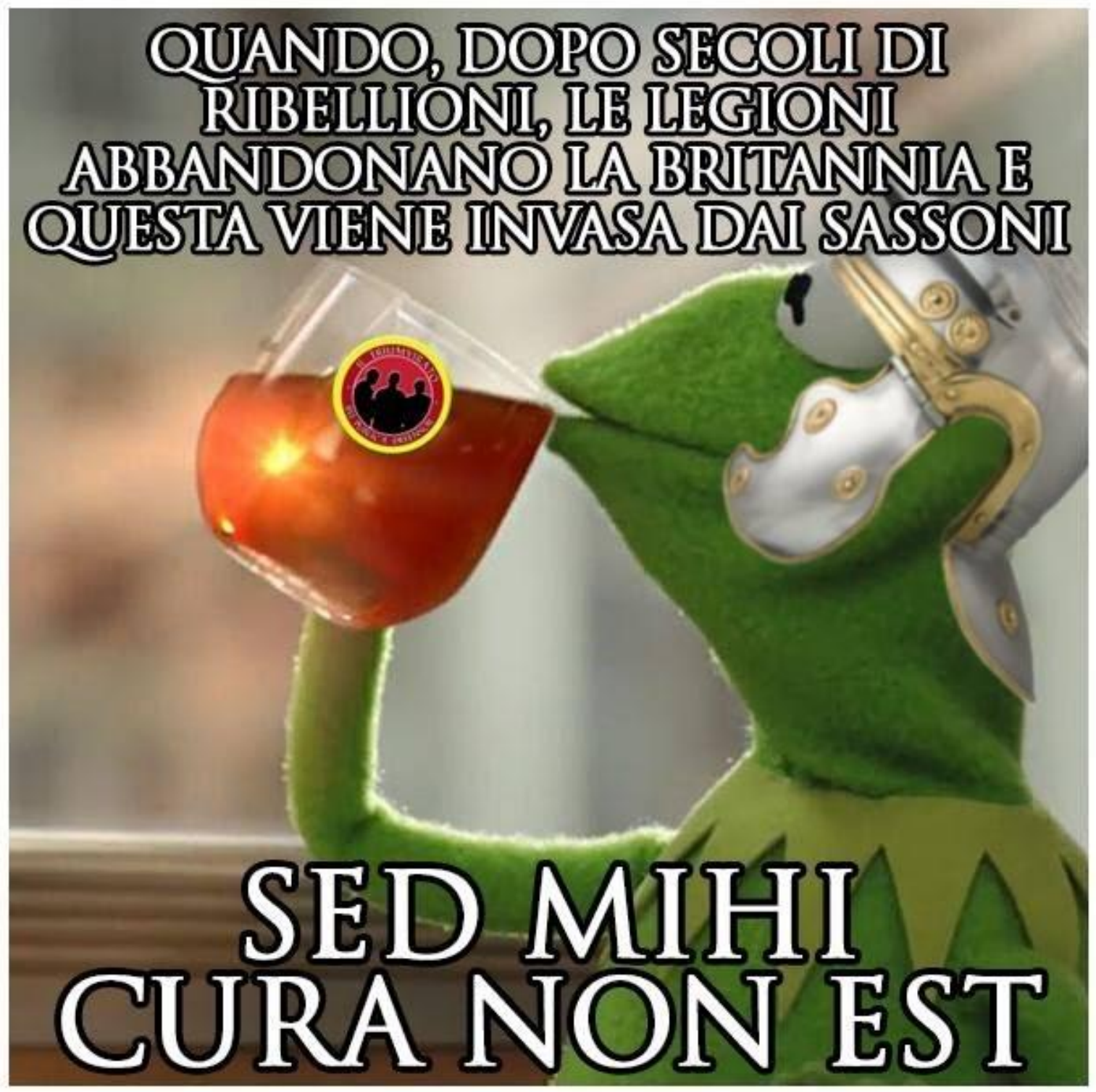

Non sfuggono alla "memeficazione" ovviamente nemmeno i politici odierni, che per la loro immagine pubblica rappresentano un simbolo immediatamente riconoscibile, in grado di stabilire un contatto con una larga fetta di utenti. È ad esempio il caso di Silvio Berlusconi e della sua celebre immagine durante le ultime consultazioni per la formazione del governo. In questo caso, il meme è generato usando il famoso ritornello utile ai liceali che studiano latino "spero, promitto, iuro reggono l'infinito futuro". 


\section{SPERO PROMITTO IURO}

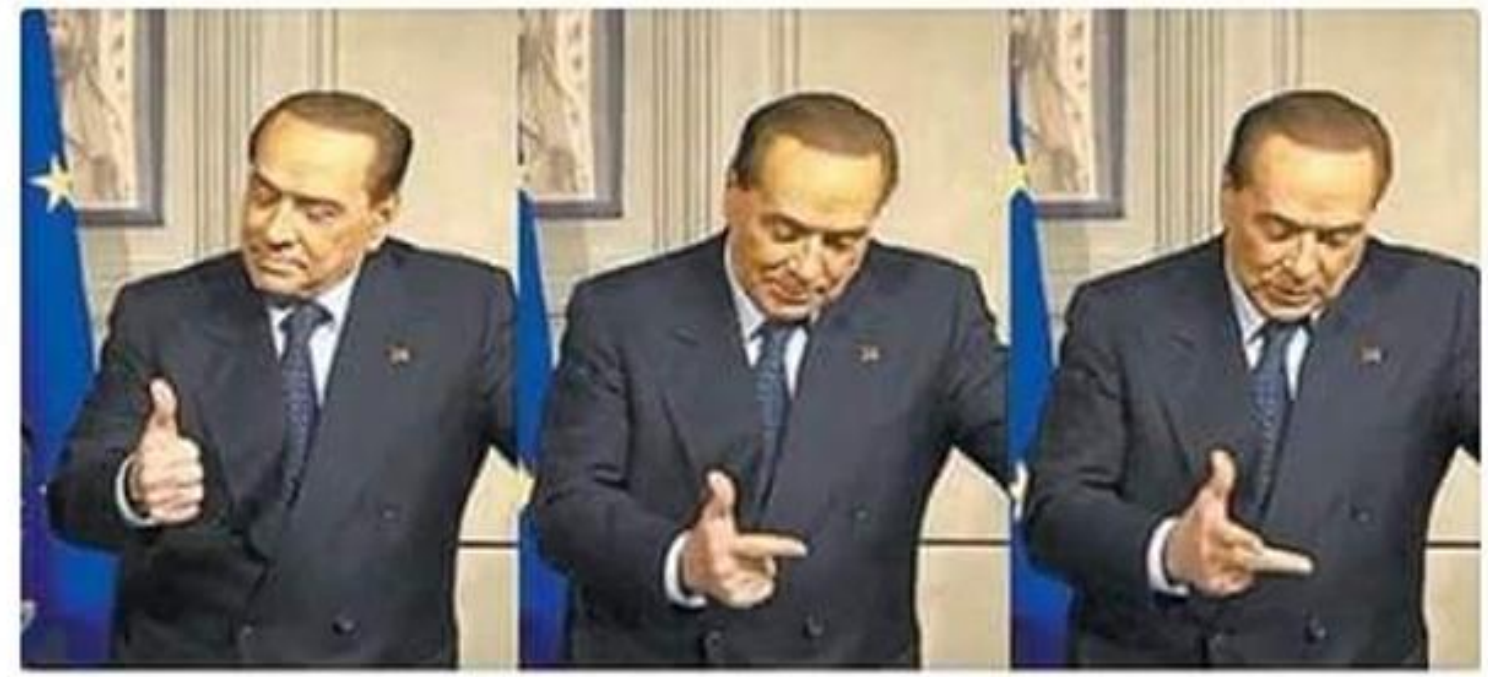

\section{Medioevo}

Dello stesso meme esiste anche una versione "medievale", legata alle caravelle di Cristoforo Colombo. In questo caso, l'ex premier enumera i nomi Nina, Pinta e Santa Maria. L'immagine risulta altrettanto buffa e come l'altra può rappresentare uno strumento utile per assimilare una nozione: in quel caso i verbi latini, in questo i nomi delle tre navi. Si tratta per altro di un ottimo esempio del meccanismo di riproducibilità e trasferibilità, che - come si è scritto - è uno dei pilastri alla base della diffusione del fenomeno. 


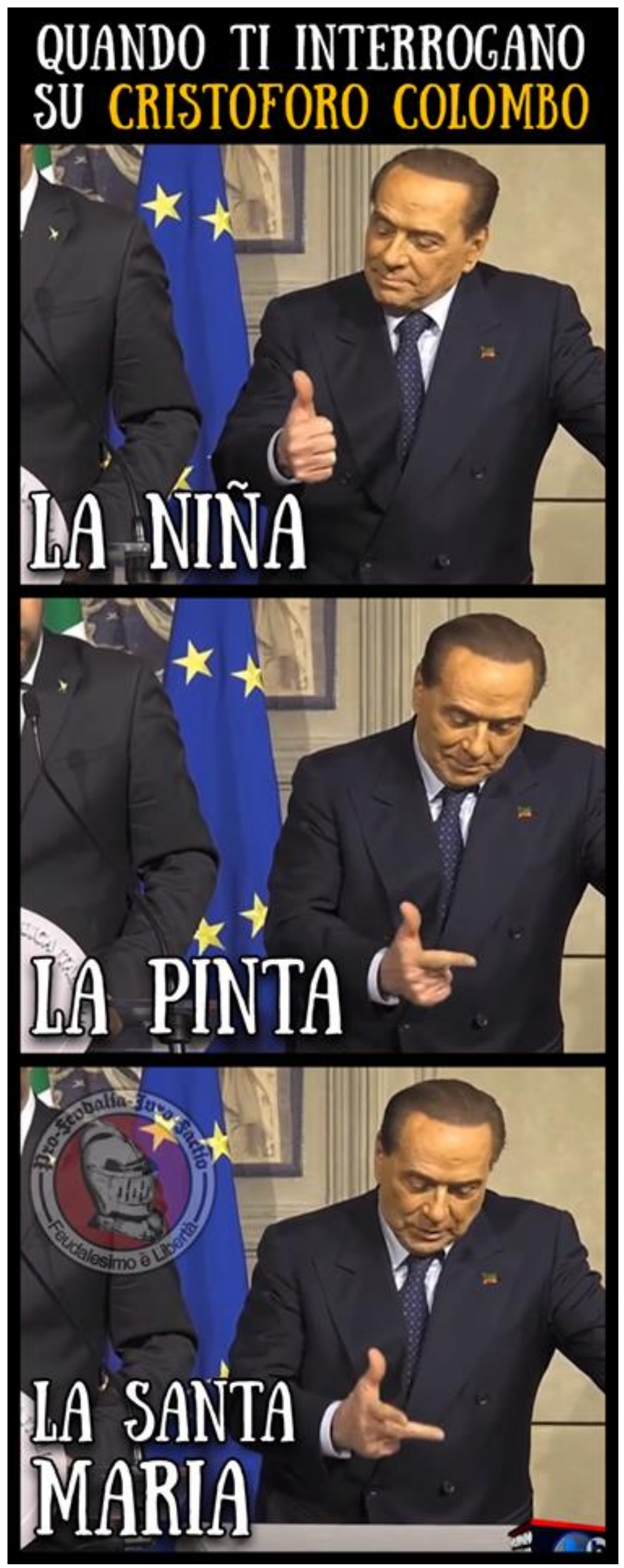


Sempre in tema di Medioevo e attualità, è di particolare interesse anche il meme seguente, diffuso su internet con diverse varianti. In questo caso, il protagonista mostra di fuggire alle tentazioni della Siria moderna agognando il Principato di Antiochia, figlio delle Crociate. Il meme è piuttosto forte, considerando l'attuale situazione in Siria, ma è un modo per ricordare la travagliata situazione che da quasi mille anni vive il Medioriente. 

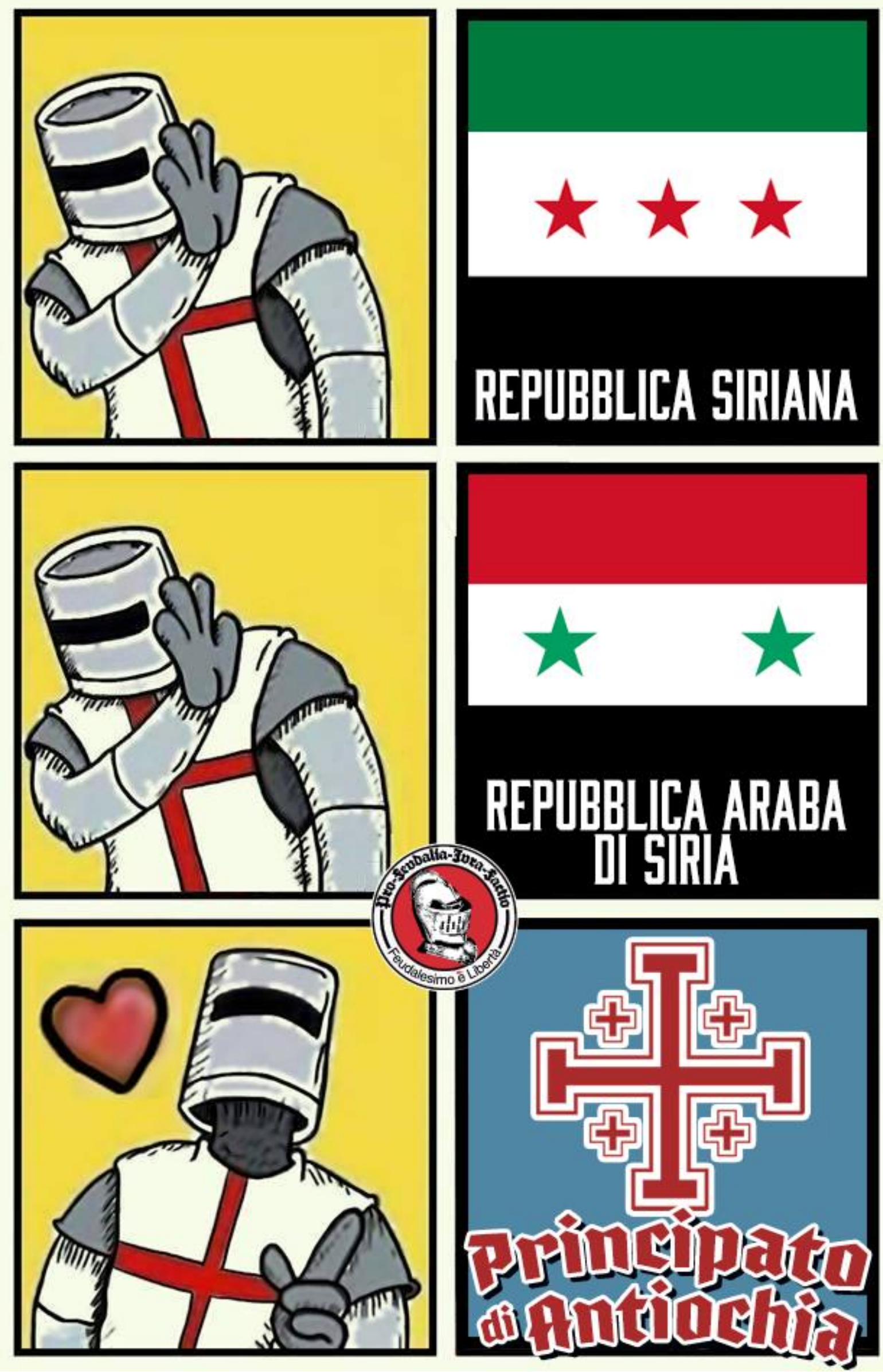


\section{Storia militare}

I meme riguardanti la storia militare hanno subito, rispetto ai meme più tradizionali, una ulteriore evoluzione "invadendo" il campo dell'animazione e appropriandosi dei personaggi e delle situazioni di celebri cartoni animati, il cui dinamismo riesce a trasmettere, a volte con parecchia attinenza storica, la situazione che viene mostrata. Un lavoro peculiare in questo senso è stato svolto dai gestori della pagina Youtube "Cartoon History Memes", i quali - sfruttando proprio spezzoni di cartoni animati celeberrimi come Tom\&Jerry o Spongebob - riescono a riassumere interi conflitti o fasi cruciali di essi con chiarezza sorprendente, semplicemente sovrapponendo le bandiere giuste ai personaggi giusti.

Eccone un esempio: Il conflitto tra Germania nazista e Unione Sovietica durante la Seconda guerra mondiale.

E' possibile notare la precisione con cui vengono nominate le varie offensive lanciate dai sovietici, disposte anche in ordine cronologico lungo la durata dell'intera clip.

\section{I grandi totalitarismi del Novecento[11]}

Quando si tratta di meme sui totalitarismi del Novecento, occorre tenere presente che è difficile scherzare su periodi storici che hanno un portato così tragico, fatto di violenza diffusa, violazioni sistematiche dei diritti umani e politiche di genocidio. Questo va anche al di là delle logiche implicazioni dovute al fatto che siamo dinanzi a vicende relativamente vicine da un punto di vista cronologico - rispetto all'Impero Romano, al Medioevo o all'età moderna - e che quindi hanno ricadute più importanti e pregnanti sul presente. Di conseguenza questo tipo di meme è il più raro $\mathrm{e}$ difficile da trovare e da studiare organicamente. Inoltre, anche su ciascuno dei tre totalitarismi esistono suscettibilità diverse: il Nazismo rappresenta tuttora un tabù sul quale è difficile fare satira e ironia; lo Stalinismo invece, alle nostre latitudini è percepito come alquanto distante, perché meno connesso con la nostra storia nazionale; valutazione diametralmente opposta a quella sul fascismo, tema sempre molto (e sempre più) "caldo" e per questo oggetto di accesi dibattiti pubblici. Il problema, storico e culturale, è troppo complesso e importante per essere affrontato e sviscerato in questo articolo, ma è inevitabile - ad esempio - ponderare quanto la svolta apologetica sia un'insidia molto frequente anche quando si cerca di fare del semplice umorismo (figuriamoci quando si intende addirittura "semplificare" la storia). Ne sono la prova le molte pagine su social network chiuse per segnalazioni non sempre fondate.

\section{Meme sul Fascismo[12]}

A questo filone appartiene Mvsolini, una pagina Facebook ora non più esistente (ma si trovano diverse immagini nel web) che utilizzava la celebre immagine di Mussolini con in testa l'elmo militare, sovrapponendo il viso di un cane a quello del dittatore. La parte testuale - che è il vero fulcro ironico - reinterpreta frasi celebri del fascismo e del neofascismo in chiave canina: da "credere, obbedire, combattere" si passa quindi a "credere, obbedire, croccantini" e da "Molti nemici, molto onore" (che tuttavia non è una frase di Mussolini, ma ampiamente riferita a lui e utilizzata dai nostalgici del Ventennio) a "Molti mici, molto onore". Elemento peculiare, che denota una certa conoscenza storica, è l'uso della lettera $\mathrm{V}$ al posto della $\mathrm{U}$. In definitiva tuttavia, il messaggio veicolato risulta piuttosto impreciso e semplicistico, ancorché assai divertente. 

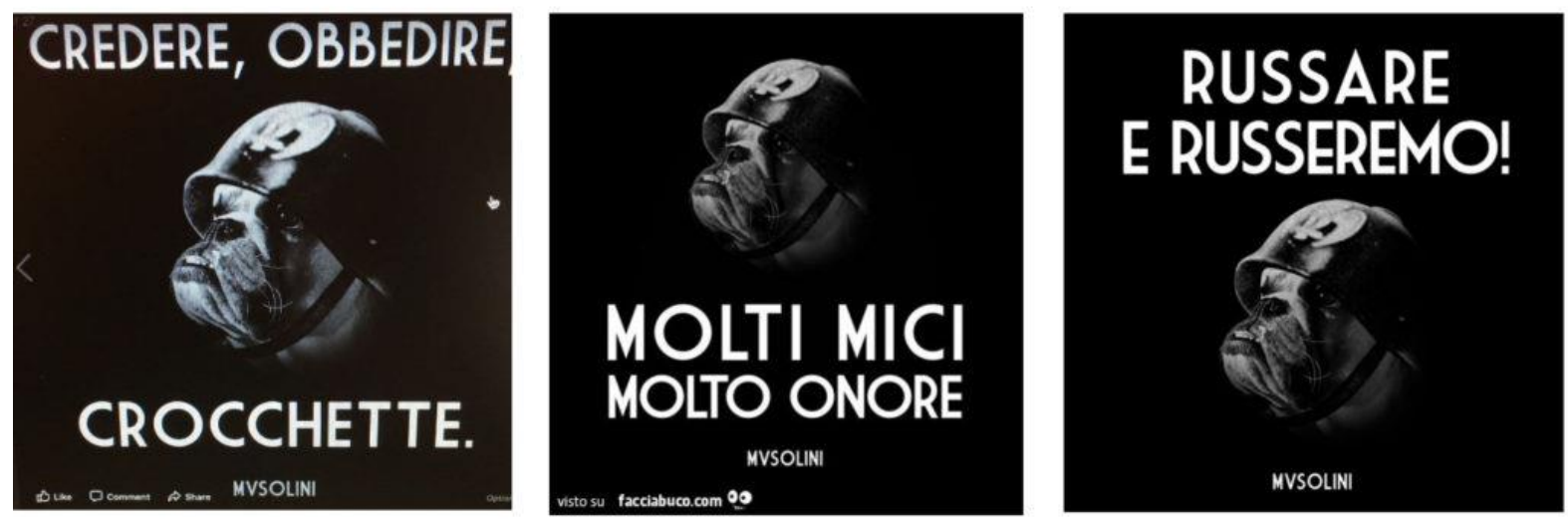

Un altro esempio simile era la pagina "Mussolini che fa anche cose buone"[13]. Rispetto all'inizio della nostra indagine, che è datata marzo-giugno 2018, la pagina non è più on line, a conferma di quella volatilità a cui si accennava poc'anzi.

\section{Meme sul Nazismo}

Il più celebre meme sul nazismo è sicuramente un video, che però non è un'immagine storica propriamente detta, perché si tratta di una fiction: è la famosa scena nel bunker di Berlino recitata da Bruno Ganz ne "La caduta" (Downfall)[14], a cui vengono abbinati i sottotitoli più disparati, riferiti a temi storici o di attualità, dalla politica allo sport. Oltre ai filmati su Youtube, esistono anche svariate pagine Facebook che li pubblicano e ripropongono. La scena viene spesso intitolata, e quindi identificata, come "Hitler scopre che..." (Hitler finds out that ...) o "Hitler reagisce a..." (Hitler reacts to.). L'audio è originale in Tedesco e il grande successo è dovuto forse anche al fatto che pochi (soprattutto alle nostre latitudini) lo capiscono davvero. I suoi toni duri e la recitazione isterica, mimeticamente riuscitissima, di Bruno Ganz lo rendono pertanto adattissimo a essere usato come un mero miscuglio di immagine e suono.

\section{$\underline{\text { Playlist completa con le versioni in italiano finora uscite }}$}

Come già accennato, un aspetto curioso e non trascurabile di questo meme è che in effetti non siamo di fronte al vero personaggio storico (Adolf Hitler), ma ad un attore che lo interpreta. Si è quindi generato un meccanismo che si potrebbe definire di "transfer", perché l'Adolf Hitler interpretato da Ganz è diventato quasi "Più Hitler di Hitler stesso". O meglio, più simile allo stereotipo di Hitler.

Allargando lo spettro di indagine, è possibile reperire un discreto numero di meme (quasi tutti in inglese) su siti come Imgflip e Memegenerator. Si tratta per lo più di immagini storiche del dittatore, dai primi piani "istituzionali" alle foto pubbliche usate in vario modo, associate a frasi che tentano di ironizzare (con scarso successo, va ammesso) sull'assonanza tra le parole Juice (succo) e Jews (ebrei) o sul termine GAS, che negli Stati Uniti significa benzina.

L'esempio più particolare, e che esplicita le maggiori e più raffinate conoscenze storiche, riguarda il sito web Hipster Hitler (conosciuto anche come "Adolf Hipster")[15]. Nato inizialmente come meme a stile vignettistico, dopo poco tempo esso è diventato una vera e propria serie di fumetti. 

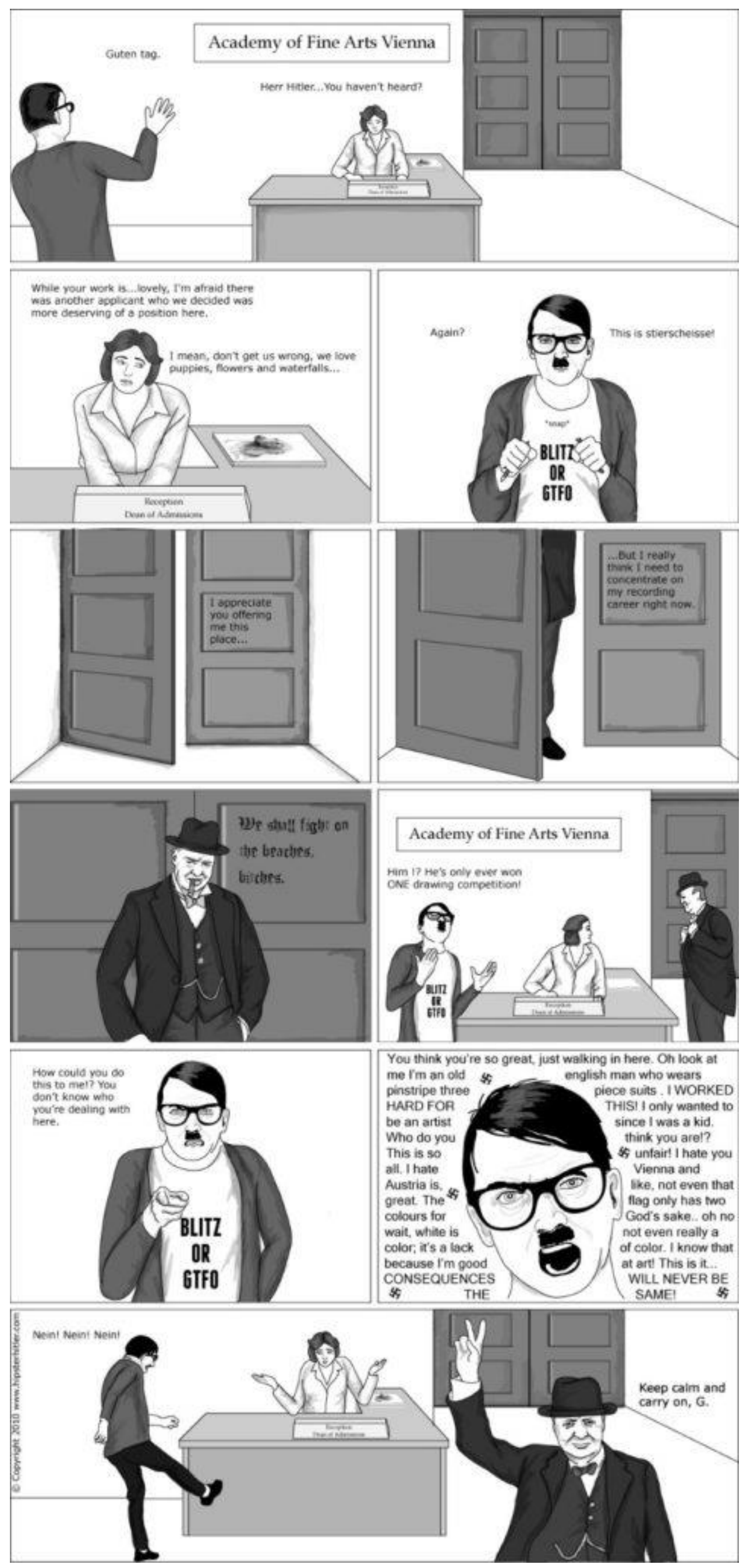


\section{Meme sullo Stalinismo}

Decisamente minoritari, soprattutto alle nostre latitudini (per motivi storici e culturali facilmente intuibili), sono i meme su Stalin e lo Stalinismo. All'estero, e in lingua inglese, se ne trovano già di più numerosi, benché non tanto quanto lo siano quelli su Hitler. Citiamo perciò il più vecchio, ovvero Stalin Says[16]. Creato nel giugno del 2011 sul sito Memegenerator, il meme fa generalmente riferimento (con umorismo che potremmo definire "nero") alle grandi purghe e ai Gulag, e in esteso all'autoritarismo del regime comunista.

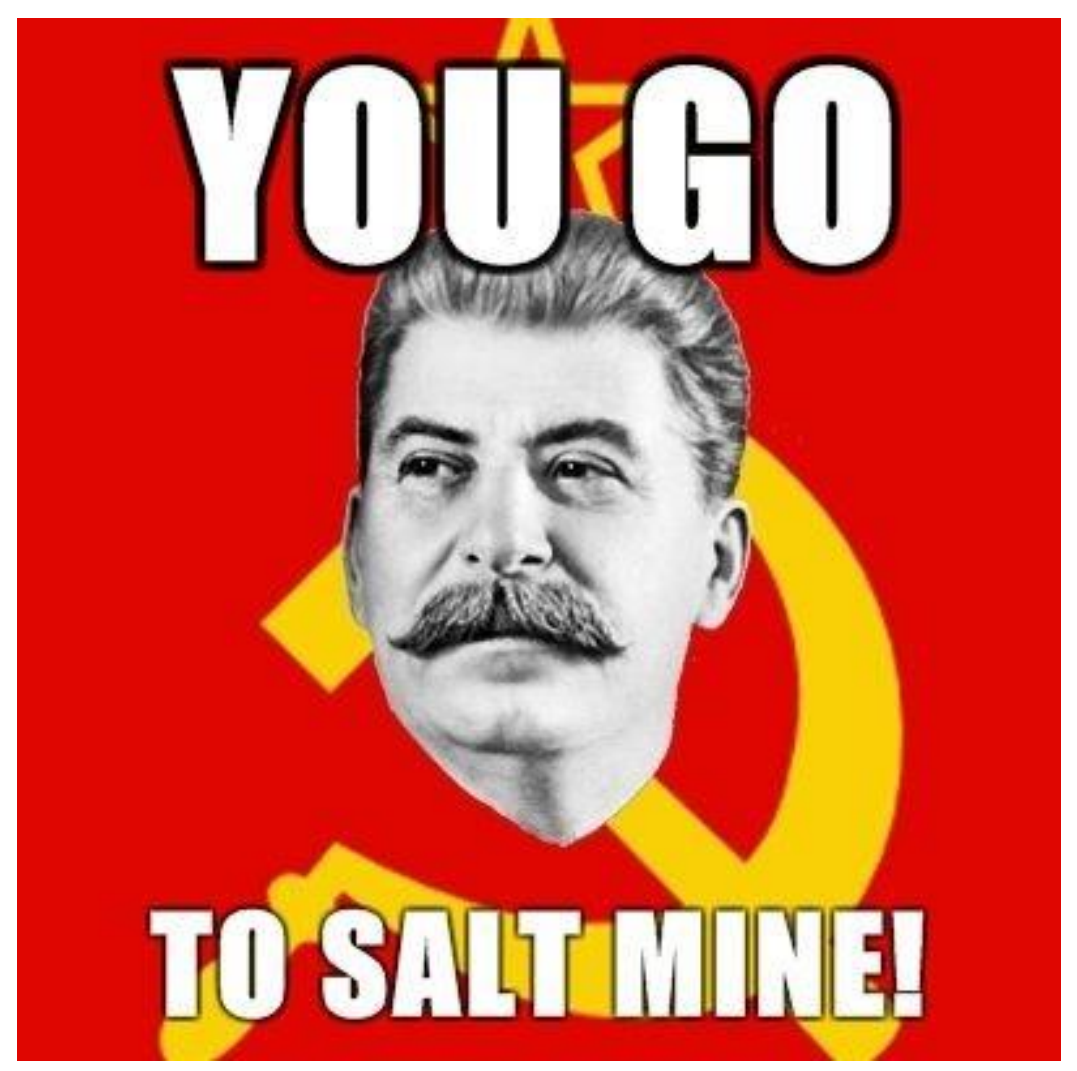

Da questa rapida panoramica emerge un aspetto importante e imprescindibile, che accomuna tutti e tre i casi: i meme sui grandi totalitarismi del Novecento sono in buona parte meme sui dittatori e non è difficile comprenderne il motivo. Il meme usa l'immagine come contenuto riprodotto e riproducibile all'infinito. All'interno di ciascuno dei tre totalitarismi, l'effige del dittatore rappresentava il fulcro dell'iconografia e della propaganda. Il culto della persona e l'idolatria del leader trovano qui una sorta di contrappasso dantesco, con ironie spesso feroci su ritratti usati un tempo a scopo celebrativo.

\section{La Prima repubblica}

La Prima Repubblica è chiaramente un argomento di nicchia limitato al contesto italiano, meno conosciuto all'estero e relativamente meno studiato dalla storiografia. La platea di prosumers di questi meme è pertanto decisamente più ristretta, ma per contro possiede una profonda conoscenza di quel periodo storico e usa un umorismo più colto e raffinato.

Questo umorismo si basa prevalentemente su due aspetti, ben suddivisi cronologicamente. Per ciò che concerne gli anni Cinquanta, Sessanta e Settanta l'epicentro è rappresentato dalla rivalità e dall'incompatibilità tra i due grandi partiti di massa dell'epoca, ovvero il Partito Comunista Italiano 
(PCI) e la Democrazia Cristiana (DC), che era per altro specchio della polarizzazione mondiale della Guerra Fredda. Al contrario, i meme degli anni Ottanta sono incentrati sul Partito socialista italiano (PSI) e sul suo leader Bettino Craxi; un periodo raccontato come ricco ed edonistico, segnato dalla diminuzione della povertà ma anche dalla crisi delle ideologie del secondo dopoguerra.

Ottimi casi di studio su questo genere di meme sono le pagine Facebook Memecrazia Cristiana[17] e Socialisti Gaudenti[18].
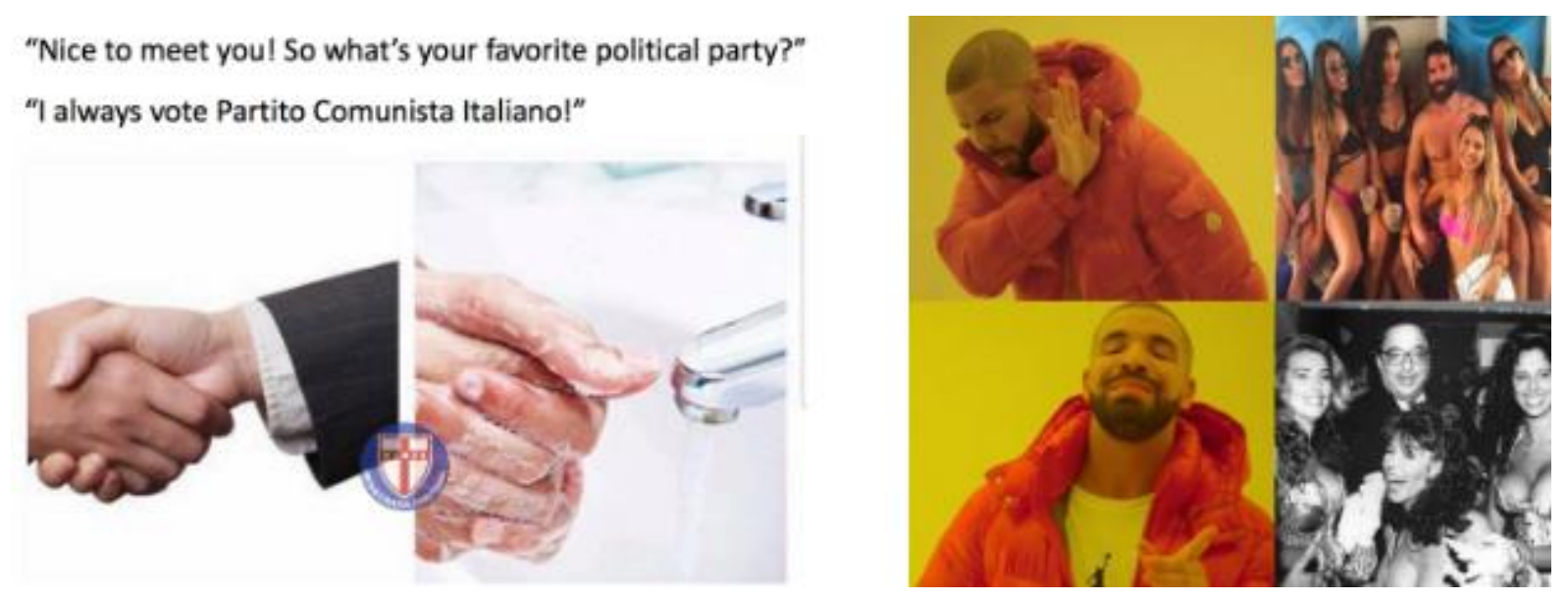

A sinistra: DC is better than PCI. Da Memecrazia Cristiana @memecratici

A destra: Gianni De Michelis meglio Dan Bilzerian (personalità di internet nota per lo stile di vita sfarzoso e dissoluto). Da Socialisti gaudenti @ socialistigaudenti

Un elemento che le accomuna è la sensazione di nostalgia della Prima Repubblica, che però non sfocia mai in apologia o in un vero desiderio di tornare indietro nel tempo. È un sentimento che oscilla tra l'ironia pura e semplice e una sensazione che ricorda per certi versi l'Ostalgie nella ex Germania orientale[19].

I prosumers di questi meme sono persone di 20-30 anni che criticano l'attuale crisi occupazionale, il caos e le carenze dell'attuale establishment italiano con un umorismo tagliente, acuto. La storia (recente) diventa quindi un pretesto per parlare frequentemente del presente[20]. Al di là di questo aspetto sicuramente rilevante, i meme sulla Prima Repubblica possono rappresentare uno strumento efficace di storia pubblica, poiché la loro arguta ironia deriva da una profonda conoscenza dell'argomento. 


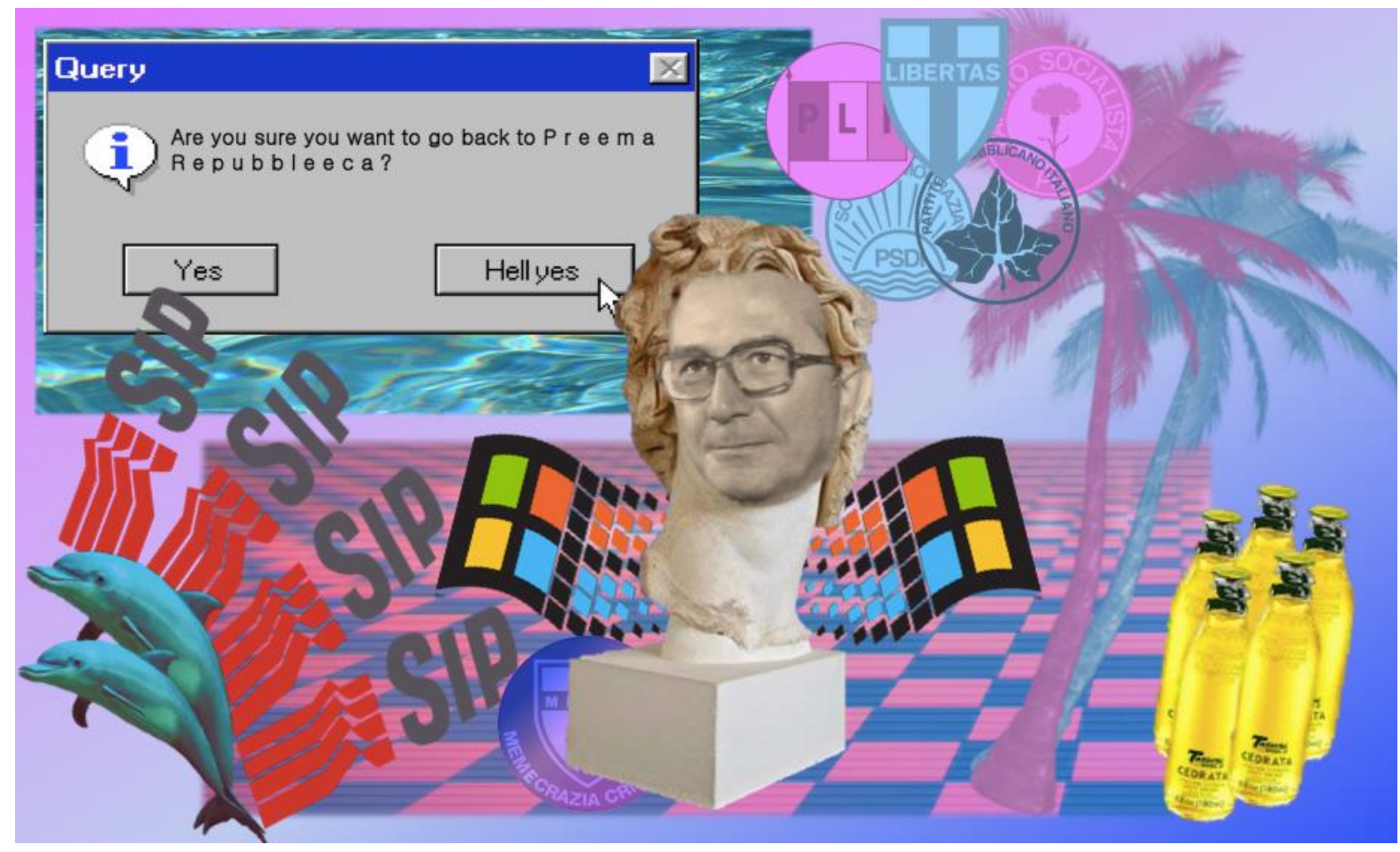

Esempio del tipo di Ostalgie dei meme sulla Prima repubblica, dalla pagina Memecrazia cristiana

Nel meme soprastante si possono rintracciare diversi elementi di interesse storico, dai simboli del Pentapartito al riferimento alla SIP come simbolo del perduto monopolio statale.

\section{Semplificare è un male}

Ogni singolo caso appena presentato meriterebbe maggiori approfondimenti, ma le esigenze di sintesi non inficiano comunque le conclusioni che si possono trarre. Se la domanda è "I meme possono essere usati come mezzo di divulgazione storica", la risposta non può prescindere dalla valutazione dei rischi e delle problematiche che questo fenomeno porta con sé. Da un lato assistiamo alla scomparsa dell'autore che, invece, nella saggistica è uno dei cardini imprescindibili dell'impianto bibliografico. Dall'altro, i meme si basano su un'estrema semplificazione e decontestualizzazione e ciò rende ovviamente impossibile dar conto del dibattito storiografico su un determinato periodo, fatto o personaggio. Proprio questa semplificazione si presta a strumentalizzazioni che in alcuni contesti (es. Alt-right[21]) sono pericolosi. L'Ironia su alcune questioni sensibili o controverse può essere un'arma a doppio taglio e per questo la loro efficacia dipende moltissimo anche dal tema trattato e dalle competenze di chi lo tratta.

I meme sui totalitarismi sono da questo punto di vista un caso emblematico: la forma breve, rapida e immediata mal si presta a rappresentare qualcosa di enormemente più complesso, in qualche caso ancora controverso o comunque sul quale non si ritiene opportuno usare gli strumenti dell'ironia. Nei casi migliori, in questi meme si rintraccia l'uso parodistico e satirico dei tratti più tristemente noti dei due totalitarismi (Shoah per il nazismo e Gulag per lo stalinismo, ad esempio) o la riduzione macchiettistica degli slogan più noti (come i casi che abbiamo visto sul fascismo). Nei casi peggiori invece - e se ne notano diversi esempi - il meme diventa apologetico, pur non nascendo con quell'intenzione. Si verifica così un traviamento dello stesso scopo per cui il suo 
creatore lo ha originato (come nel caso di Pepe The Frog[22]), ma per fortuna - e nonostante molti passi vadano ancora fatti - almeno il web ha posto i necessari strumenti di tutela.

\section{Semplificare è un bene}

Fin qui le inevitabili criticità. Eppure i meme hanno delle potenzialità altrettanto indiscutibili.

Innanzitutto si basano su un coinvolgimento attivo degli utenti nella loro rielaborazione. Usando immagini note riutilizzate più volte, hanno una diffusione vastissima e trasversale, che travalica l'argomento storico; cosicché l'immagine di Berlusconi che conta con le dita può valere per la romanità, il medioevo, ma anche per ricordare i goal subiti da una squadra nel derby. I meme inoltre, sfruttano un linguaggio semplice e immediato, che obbliga i loro creatori a cimentarsi in una sintesi estrema. Le esigenze di sinteticità spingono infatti il creatore a individuare con maggior precisione i concetti e i punti cardine delle questioni, lo allena a essere un migliore "divulgatore" e a essere più efficace nel trasmettere una tesi, una nozione o un messaggio. In questo modo il meme, come nel caso di quello sul crociato che desidera il Principato di Antiochia, riesce a trattare con humour anche questioni complesse. Sul versante opposto, anche il fruitore è spinto a uno sforzo non banale di decodifica. Comprendere un meme significa infatti saperne leggere l'intertestualità. Riderne può stimolare ad approfondire per afferrarne meglio il senso o spingere a cercare spunti storici o storiografici per una replicazione o emulazione all'interno della comunità virtuale o di un gruppo di amici, coetanei o compagni di studio.

\section{Tutto questo è public history?}

Quando ad occuparsi del processo generativo dei meme sono persone con conoscenza (quand'anche non formazione) storica, gli esempi virtuosi sono numerosi, con buoni risultati sia in termini di divulgazione che di efficacia, dovuti proprio alla semplicità e all'immediatezza del linguaggio. L'intermediazione di persone o enti qualificati è fondamentale in questo come in molti altri ambiti. Ne è una riprova il fatto che in alcune scuole (poche per il momento) i meme vengono usati dai docenti come strumento nelle esercitazioni di storia, con risultati limitati all'apprendimento nozionistico, ma comunque incoraggianti e in apparenza soddisfacenti. Ad esempio, per enfatizzare o sottolineare un evento storico o una data, l'insegnante può stimolare gli studenti a importare un'immagine in un programma di creazione di meme e a creare il proprio meme con un sottotitolo spiritoso, che ricordi quello stesso evento o quella stessa data. In questo modo oltretutto si aumenta il coinvolgimento della classe, così come la soglia di attenzione e la partecipazione degli alunni.[23]

Si tratta in questo caso di un "uso creativo" dei meme, attraverso il quale l'insegnante può stimolare l'inventiva degli alunni e al contempo verificare il grado di apprendimento al termine di una lezione, di un'unità didattica o di un percorso espositivo. Quest'ultimo aspetto li rende per altro un interessante strumento anche per i musei che vogliano cimentarsi nell'allestimento di laboratori didattici. Ancora una volta è la necessità di sintesi, seguita a un momento di debriefing con l'insegnante o il "master", a costituire il fulcro della sfida, perché solo comprendendo a fondo un percorso si riesce a sintetizzarlo. In ambito didattico tuttavia, esiste almeno un altro importante utilizzo di cui i meme possono essere oggetto e che potremmo definire "uso di verifica e confutazione". In quanto spesso espressione di luoghi comuni storiografici, i meme rappresentano un buon punto di partenza per riflettere e approfondire tesi, eventi o concetti, giungendo così a 
interpretazioni storiografiche credibili, che vadano oltre lo stereotipo e arrivino ad ampliare o anche (e soprattutto) a sovvertire completamente il significato incarnato dal meme stesso.

In quest'ottica, “insegnare storia attraverso i meme" è un' espressione che acquisisce nuovo senso e sostanza e ci consente di allargare ulteriormente lo spettro di rilfessione, fino a valutare l'efficacia sociologica e storiografica dello strumento. I meme costituiscono infatti degli indici piuttosto sensibili per analizzare la narrazione mediatica di una determinata tematica (anche di politica o attualità) o per riflettere su come un periodo storico viene visto ai giorni nostri. In questo caso è utile leggere non solo i meme ma la loro capacità di creare discussioni e reazioni, specialmente negli utenti del social network. E' un "uso interpretativo" dello strumento, che diventa quindi utile non tanto in sé, quanto per analizzare ciò che attraverso esso viene veicolato nella rappresentazione e/o strumentalizzazione (si potrebbe dire "Uso pubblico") della storia.

\section{Bibliografia}

- Börzsei, Linda K., Makes a Meme Instead. A Concise History of Memes, in «New Media Studies Magazine», feb. 2013.

- Caffier, Justin, Meme Historians Are an Inevitability, in «Vice», 20 mag. 2017, url: https://www.vice.com/en us/article/ezjmva/meme-historiansare-an-inevitability

- Cauvin, Thomas, Public History. A Textbook of Practice, Routledge, New York-London 2017.

- Davison, Patrick, The Language of Internet Memes, in The Social Media Reader, Michael Mandiberg (a cura di), New York University Press, New York 2009, pp. 120-134.

- Dawkins, Richard, The Selfish Gene, 2a , Oxford University Press, Oxford 1989.

- Knobel, Michele, Colin Lankshear (2005). Memes and affinities: Cultural replication and literacy education, in «Annual Meeting of the National Reading Conference», Miami, 2005.

- Lolli, Alessandro, Antologia memetica, in «Not», 18 dic. 2017, url: https://not.neroeditions.com/antologia-memetica/.

- Lolli, Alessandro, La guerra dei meme. Fenomenologia di uno scherzo infinito, effequ, Orbetello 2017.

- Nagle, Angela, Kill All Normies. Online culture wars from 4chan and Tumblr to Trump and the altright, Zero Books, Winchester 2017.

- Salvatori, Enrica, Storia digitale e pubblica: lo storico tra i 'nuovi creatori' di storia, in Bertella Farnetti et al., Public History. Discussioni e pratiche, Mimesis, Milano-Udine 2017, pp. 189-197.

- Shifman, Limor, Humor in the Age of Digital Reproduction. Continuity and Change in Internet-Based Comic Texts. in «International Journal of Communication»,.l, 2007, pp. 187-209.

- Wilkins, Kim, Valhallolz: Medievalist humor on the Internet, in «Postmedieval: a Journal of Medieval Cultural Studies», V, 2, estate 2014, pp. 199-214.

- Zittrain, Jonathan L., The Future of the Internet - And How to Stop It, Yale University Press, . New Haven 2008.

Note:

[1] "An Internet meme is a piece of culture, typically a joke, which gains influence through online transmission", in R. Dawkins, The Selfish Gene, 2a ed., Oxford University Press, Oxford 1989, opera in cui l'autore sostiene che una parte considerevole del comportamento umano non proviene da geni (le unità di base della genetica) ma dalla cultura. 
[2] Enciclopedia Treccani on line [http://www.treccani.it/vocabolario/meme_\%28Neologismi\%29/], url consultata il 17 dicembre 2018

[3] A. Lolli, Antologia memetica, in «Not», 18 dic. 2017, [https://not.neroeditions.com/antologiamemetica/], url consultata il 27 luglio 2018

[4] J. Caffier, Meme Historians Are an Inevitability, in "Vice", 20 maggio 2017

[https://www.vice.com/en_au/article/ezjmva/meme-historians-are-an-inevitability], url consultata il 17 dicembre 2018

[5] Ibidem. Citazione originale: "a unit of culture defined by the people using it that gets mutated along the way"

[6] J.L. Zittrain, The Future of the Internet - And How to Stop It, Yale University Press, New Haven 2008, pag 71 e L. K. Börzsei, Makes a Meme Instead. A Concise History of Memes, in «New Media Studies Magazine», feb. 2013, pp. 10-12

[7] L. K. Börzsei, Makes a Meme Instead. A Concise History of Memes, in «New Media Studies Magazine», feb. 2013

[8] A. Nagle, Kill All Normies. Online culture wars from 4chan and Tumblr to Trump and the altright, Zero Books, Winchester 2017.

[9] A. Lolli, Antologia memetica, in «Not», 18 dic. 2017, [https://not.neroeditions.com/antologia-

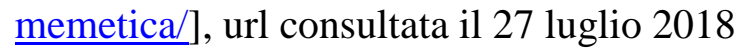

[10] M. Knobel e C. Lankshear, Memes and affinities: Cultural replication and literacy education, in «Annual Meeting of the National Reading Conference», Miami, 2005

[11] Non sono stati presi in esame i meme che hanno chiari e dichiarati intenti nostalgici o propagandistici. La scelta è assolutamente deliberata perché il fenomeno che lì si presenta, per quanto decisamente importante e interessante, esula da un'indagine che mira a interrogarsi se il meme possa o meno avere valenza di strumento per la divulgazione storica. In quei casi siamo invece di fronte di fronte a palesi intenti apologetici, che rendono la domanda del tutto superflua.

[12] Tempo fa sugli organi di stampa (ad esempio su Vice,

https://www.vice.com/it/article/evdpkn/spiaggia-fascista-di-chioggia-meme-presi-a-caso-dainternet, url consultata il 17 dicembre 2018) è stata diffusa la notizia di un lido balneare a Chioggia che aveva usato immagini del fascismo con intento nostalgico, senza rendersi però conto che fossero dei "meme". In realtà si trattava semplicemente di immagini satiriche, perché in esse era completamente assente il meccanismo di riproducibilità e di reiterazione tipico dei meme.

[13] [https://www.facebook.com/quandocenalui/], url consultata il 19 giugno 2018

[14] [https://knowyourmeme.com/memes/hitlers-downfall-parodies]. Ne esiste anche un gruppo su Facebook: [https://www.facebook.com/groups/180541862734/]. Url consultate il 18 dicembre 2018

[15] [http://hipsterhitler.com/], url consultata il 18 dicembre 2018

[16] [https://knowyourmeme.com/memes/stalin-says], url consultata il 18 dicembre 2018 
[17] [https://www.facebook.com/Memecratici/], url consultata il 18 dicembre 2018

[18] [https://www.facebook.com/socialistigaudenti/], url consultata il 18 dicembre 2018

[19] Ostalgie è un termine entrato ufficialmente nella lingua tedesca nel 1993 e sta a indicare il sentimento nostalgico sviluppatosi nei primi anni 1990 nella Germania dell'Est a seguito della scomparsa della DDR.

[20] Così avviene per altro anche in altri casi riferiti a epoche diverse. Emblematica la pagina Facebook di Feudalelismo e libertà, riferita al Medioevo ma con continui agganci all'attualità.

[21] Movimento politico nato negli Stati Uniti, non strutturato e non coeso, che non dispone di un'organizzazione centrale o di un'ideologia precisa. Promuove ideologie di destra alternative a quelle tradizionali del conservatorismo e si caratterizza per lo più come movimento subculturale. Per approfondire la questione: Pepe the Frog's Creator: I'm Reclaiming Him. He Was Never About Hate, in "Time" versione on line [http://time.com/4530128/pepe-the-frog-creator-hate-symbol], url consultata il 18 dicembre 2018.

[22] Meme tra i più popolari a partire dal 2015, nel 2016 è stato ampiamente utilizzato dal movimento di estrema destra Alt-right, contro la volontà del creatore. Per approfondire la questione: Pepe the Frog's Creator: I'm Reclaiming Him. He Was Never About Hate, in "Time" versione on line [http://time.com/4530128/pepe-the-frog-creator-hate-symbol], url consultata il 18 dicembre 2018.

[23] Sarah Mills, Memes in classroom, in Learning lift off [https://www.learningliftoff.com/memesin-the-classroom] e Sharon Serrano, 5 ways to use memes with students, in International Society for Technology in Education (ISTE) [https://www.iste.org/explore/articleDetail?articleid=858], /], url consultate il 18 dicembre 2018 